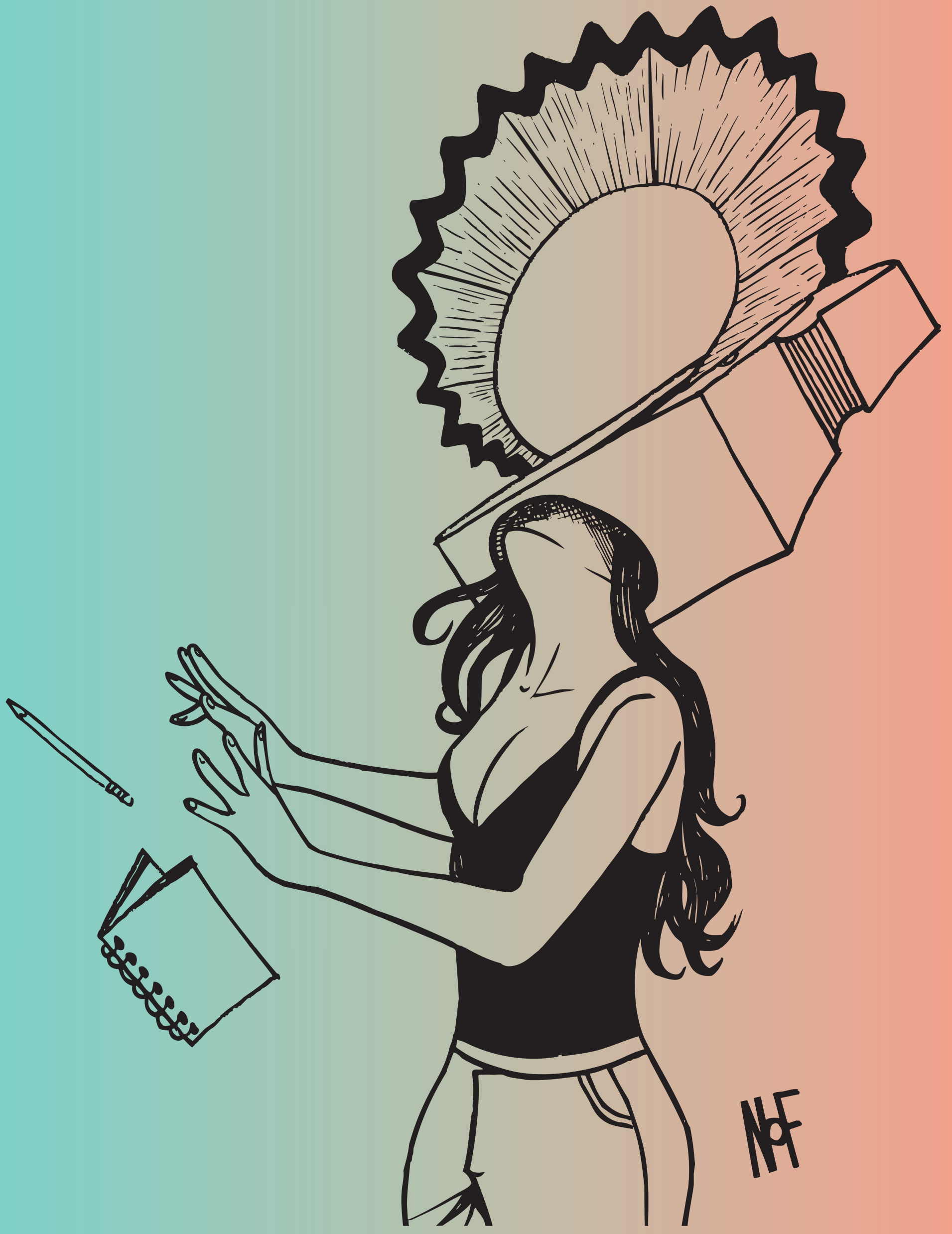




\section{Mercedes juega su \\ destino en el ecuavoley}

\section{Edwin Alcarás*}

Fecha entrega: 2014-01-23 • Fecha aprobación: 2014-02-20

P

edro, el Rocky, está retando al Puyoso. Lo mira con complicidad. Quemando el aire con sus ojos. Los demás a su alrededor esperamos en silencio una grosería ingeniosa, un insulto elegante, o al menos una mueca divertida. Pero solo dice: "Muévete, no seas maricón. O te les vas a ahuevar a unas damas". Los demás silban -silbamos- y al Puyoso no le queda otra. Esa resignación avergonzada, esa humildad falsa, significa que el pacto está sellado. El Rocky va a colocar, el Puyoso servirá y el Chuqui será volador.

* Edwin Alcarás, nació en Quito, en 1981. Es periodista y escritor. Publica crítica de cine en la revista Zoom. Ha sido profesor invitado de literatura extranjera en la Universidad Andina Simón Bolívar, sede Quito. Ha realizado sendos talleres de periodismo narrativo en Colombia, con Julio Villanueva Chang y Alberto Salcedo Ramos, ambos organizados por la Fundación para un Nuevo Periodismo Iberoamericano. 
Los apostadores aplauden -aplaudimos- con auténtica exaltación, como si fuéramos el coro de una antigua comedia (o tragedia, nunca se sabe) y como si 'el hueco' de La Marín fuera algo más que solo una cancha de ecuavoley de las cientos que, en las burocráticas tardes quiteñas, se llenan de almas hambrientas de emociones. Y esta tarde de septiembre, con el sol ahogándose entre tonos melón y nubes sucias, 'el hueco' sí parece más que solo 'el hueco’.

Las dos damas sonríen con las manos en los bolsillos de sus calentadores de tela sintética. Están acostumbradas a las escenas que genera la testosterona cuando ellas llegan a sacudir esos gallineros primitivamente masculinos. Saben que pueden ganar. Sonríen así porque lo saben. Y el Pedro, que al principio se mostraba canchero y fanfarrón, de pronto se ha puesto serio. Los USD 60 que metió en el juego empiezan a quemarle en el rincón de su consciencia donde guarda el miedo.

Mientras el enjambre de apostadores abandona lentamente la cancha, Mercedes Mena - mujer de edad indefinible, facciones finas y angostas (como dibujadas con lápiz $4 \mathrm{H}$ ) y mirada reciarecuerda la primera vez que le ganó a un hombre en el ecuavoley. El sol moribundo riza los bellos dorados de sus brazos fibrosos. Cuando aprieta los puños con ira los músculos del antebrazo se mueven como los hilos de un telar artesanal.

Era el tercer quince y le faltaba un punto para ganar, se acuerda. Estaba parada en su esquina a punto de batir cuando un patán, más desesperado que morboso, se acercó por detrás y le haló el pantalón hacia abajo. "Ese rato no me enojé. Tenía que seguir concentrada en el juego. Después de que gané, recién me di cuenta de lo que había pasado". Pero para entonces era tarde. Su primo, un ecuavoleyvolista de la escuela clásica, ya estaba corrigiendo al chistoso con una tormenta de puñetes. Entonces Mercedes entendió -como se entienden esas cosas, con el sentimiento palpitando en la piel, mezclándose con el sudor- que en el ecuavoley una mujer no solo se juega la plata sino también el respeto por su género.

Karina Hernández, la servidora de Mercedes desde hace 13 años, calienta en el centro de la cancha. Da trotecitos y salta midiendo el alto de la red. Está contenta de volver, a los tiempos, al vóley de barrio, a esa alegría brusca que es enfrentarse al prejuicio masculino. Acá no importa que ambas hayan sido vicecampeonas sudamericanas de vóley de playa en 2007, como tampoco importa que hayan ganado el título nacional de ecuavóley femenino durante 10 años. Adentro de la cancha, la realidad es más sencilla y más sincera: solo existe el momento presente. El pasado es un artefacto mental secundario que solo se usa para guiarse en la apuesta 0 , a veces, para poner apodos a la gente. $Y$ el futuro solo es admitido en forma de expectativa: un sudor frío en el alma, un vértigo en el estómago, que dura generalmente entre una hora $\mathrm{y}$ una hora y media.

Son un equipo de dos. Las voladoras oficiales están cumpliendo otros compromisos, la una en Cuba preparándose para los Juegos Panamericanos de vóley de playa, y la otra en Pallatanga atendiendo las faenas amatorias de un matrimonio recién formado. Así que el

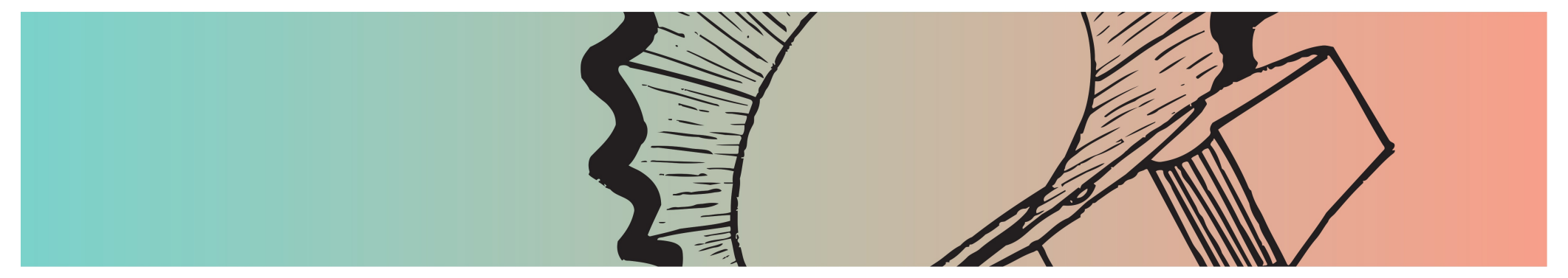


tercer miembro ha tenido que venir de las mismas huestes del Puyoso y el Pedro. El Tobi es un cincuentón robusto de bigote ralo y vampíricas entradas en la frente, rigurosamente vestido para la ocasión: zapatillas negras de pescador, pantaloneta amarilla de poliéster y camiseta de una conocida marca de pintura. Sabe bien a lo que se ha metido, por eso soporta con filosofía los silbidos que el respetable le lanza desde los graderíos y las perlas con que lo adornan: "Esa voladora se parece a mi suegra" o "Le han puesto a volar a la señora del morocho".

El Tobi solo sonríe sereno, seguro de sí mismo, como si supiera algo que los demás ignoramos, Grita: iibolaaaa!! y el partido comienza.

$* * *$

Sentado entre el público, fumando con avidez, está Hugo Bermeo, conocido de este lado de la cancha como el 'Llaverito'. Él ha sido el autor intelectual de este partido mixto y mi contacto en el mundo del ecuavoley. Hace tiempo, cuando le pregunté cuál era la mejor jugadora de la ciudad, me clavó la vista con el ceño fruncido, con una expresión característica suya, entre feroz e incrédula, como si le hubiera preguntado si la pelota es redonda o cuadrada. Toma un tiempo darse cuenta de que esa es una beligerancia meramente teatral, bastante común entre los ecuavoleyvolistas. Un advenedizo distraído podría confundir fácilmente los gritos y las mentadas de madre (que en la cancha son como golpes inofensivos de confianza entre amigos, muestras ásperas de camaradería) y sacar la conclusión apresurada (y falsa) de que este es un deporte agresivo.

Luego de pensar detenidamente, el 'Llaverito' dijo con una sonrisa de niño: "La Mercedes. Hay varias que van a las canchas, pero, así de élite: la Mercedes".

Estábamos en la madre de todas las canchas quiteñas, Chimbacalle, corazón histórico de este deporte popular y amateur. Hasta hace unos años cuando alguien se sentía lo suficientemente temerario y quería entrar al valhala del ecuavoley tenía que ir a fajarse allá, con los duros de verdad. Allí se repartían los certificados de honorabilidad y las licencias para apostar en serio. Pero la ciudad se desbordó violentamente en las últimas décadas y se disolvió la geopolítica de este juego con la proliferación de nuevos núcleos pequeños y dispersos. Sin embargo, Chimbacalle aún conserva un aire de su antigua condición de centro político y económico del voley. Muchos de las decenas de feligreses de esta cancha alguna vez fueron también figuras prestantes con gallada y barra incondicionales, aunque hoy sus destrezas deportivas se limiten al naipe, la lengua y la memoria.

Cuando el 'Llaverito' nombró a Mercedes, estos doctores de la ley se masajearon las barbillas con solemnidad, juzgando antes de asentar un veredicto. En el ecuavoley, como en toda actividad del espíritu que todavía no ha sido normada por la participación del Estado, la tradición funciona como la máxima ley, la leyenda es la única jurisprudencia. Los partidos memorables -esos sucesos épicos- se transmiten oralmente de vos a vos, como si fueran mitos o poemas anónimos. Mercedes Mena
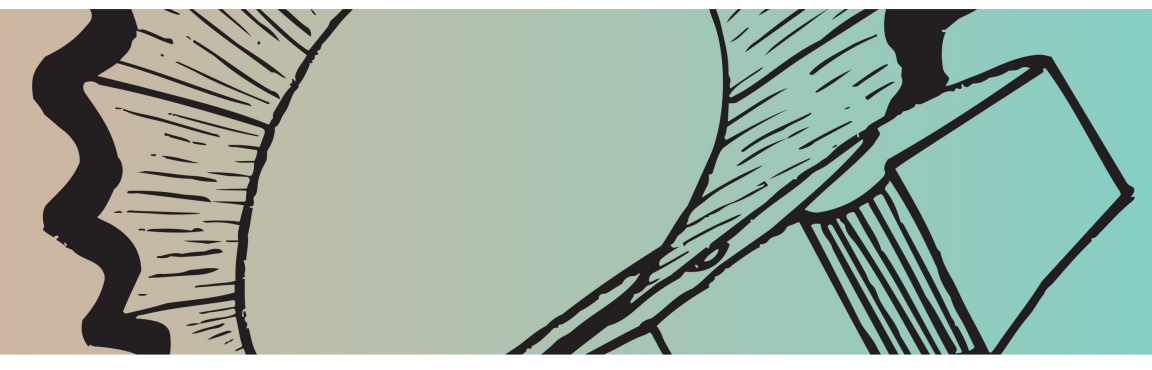
ha entrado, con argumentos categóricos, en esa fábula popular y espontánea del vóley quiteño. Los doctores confirman el juicio del 'Llaverito'. Esa mujer delgada y fibrosa es una de las pocas admitidas en la historia que todos los días se escribe en las canchas. En el día a día, son escasas las jugadoras de estilo clásico: o sea las que pueden pasarse todo el día jugando o apostando, con sol o con lluvia, arrastradas por una pasión más fuerte que ellas. Pero existen.

En la Federación de Ligas Barriales y Parroquiales de Pichincha, Fedebip, no existe una estadística de la cantidad de mujeres que se dedican habitualmente a este deporte, aunque en los hechos se admite que son suficientes para organizar un campeonato anual de ecuavoley femenino que lleva 12 años, aunque aún no ha logrado fijar una fecha estable. Con 10 títulos, las campeonas históricas e invictas de esa competencia son Mercedes y Karina. Entre 1998 y 2008, cuando se retiraron, no hubo trío que les hiciera frente.

La ausencia de información oficial sobre este deporte popular, es totalmente comprensible si se sabe que el ecuavoley aún no ha podido elevarse a la categoría profesional, pese a los esfuerzos de varias generaciones de deportistas. Eso, por supuesto, no quiere decir que no existan profesionales. Los hay y espectaculares (en el sentido literal del término), unos medallistas olímpicos en potencia (si es que alguien lograra convencer algún día a la Comisión Olímpica de las ventajas, físicas y competitivas, de jugar en equipos de a tres y con el balón número cinco, reglamentario del fútbol). Pero como a la realidad no le importan ni las leyendas ni los sueños, a los profesionales de este deporte les toca andar de incógnitos, fungiendo de taxistas, médicos, profesores, albañiles, administradores de empresas o, como Mercedes, empleados públicos.

De lunes a viernes ella rige la ventanilla de Atención al Público en una empresa municipal. El uniforme correctamente planchado, el maquillaje austero, la mirada invariablemente fuerte, y las manos tersas y distinguidas... todo indicaría que nunca en su vida batió un balón húmedo y terroso. Con intachable sonrisa profesional, la funcionaria ayuda a resolver los problemas de los clientes, da indicaciones, los despacha con sutileza. Mientras, la Mercedes que grita, y que pasa la bola con violencia sobre los 2,85 metros de la red oficial, y que hace retorcerse a los más puestos, esa ecuavoleyvolista de élite, palpita en silencio, al filo de la realidad, calentando incansablemente en lo oscuro de la consciencia. $Y$ del recuerdo.

Ella y Karina se retiraron de la actividad continua hace tres años, a los 40 y 30 respectivamente, luego de una carrera brillante de logros en alineaciones de dos, tres y seis jugadoras. La realidad pudo más. En 2007 Karina tuvo que renunciar a un puesto en una empresa grande y prestigiosa que le dio a escoger entre los juegos panamericanos (a los que el Ecuador, con ellas, clasificó por primera vez en vóley de playa) y su trabajo. No había mucho que pensar. Renunció. Ecuador quedó quinto, nada mal para ser primera vez. Pero a Ecuador no le importó. Cuando volvió, Karina tuvo que buscar empleo de nuevo y se vio forzada a dejar las canchas. Sin su compañera oficial, Mercedes también abandonó las rutinas de entrenamiento y se refugió en el confiable y familiar ecuavoley. Ahora las dos mujeres se reúnen cada dos o tres semanas, cuando tienen ganas de entretenerse un poco, recordar otros tiempos y someter a los hombres.

$* * *$

El Tobi intenta salvar una bola que no era mala sino pésima y la manda afuera de la cancha. El primer doce (los juegos en serio abrevian los tres últimos puntos) ha sido una feria de regalos para el Pedro y el Puyoso. La confianza ha vuelto a regar sus rostros. Están lucrando de la veta de oro que encontraron atrás, mientras el Tobi no termina de 
hallarse en la cancha. Mercedes no muestra emociones. Tiene el ceño fruncido y no festeja cuando marca algún punto, solo cierra los puños, baja brevemente la cabeza y corre al puesto de batida. Es un trabajo laborioso -y la mayoría de veces inútiltratar de revertir la compleja maquinaria psicológica de la derrota. En efecto, el primer tiempo termina 12 a 7 .

En el segundo tiempo, Mercedes, Karina y el Tobi saltan al vacío. Tienen todo que perder (o sea noventa dólares) y todo el público en contra, incluido el juez de la contienda que, desde lo alto de la red (parece un querubín cimarrón y fumador) proclama su parcialidad con sinceridad pasmosa. El equipo ensaya a entenderse con estrategias numéricas que masculla la ponedora en cada nueva batida con la boca tapada con el balón. La serie es infantilmente misteriosa: "Dos ahí mismo y dos adelante", "Dos solo adelante" "Dos solo en los puestos". Así se indican las veces que se mantendrán en los lugares clásicos del juego: todo el lado derecho para Mercedes y el izquierdo dividido entre la servidora (parada al pie de la red) y el volador (en el centro). Y las veces que rotarán para cubrir a la ponedora.

La estrategia funciona con una eficiencia que espanta. Pedro, el Rocky, cae repetidamente en la trampa de la bola bajita puesta con ternura en las comisuras delanteras de la cancha. El respetable se arrebata, pifia y muge, como un demonio borracho. El 'Llaverito' ríe a carcajadas y, haciendo altavoz con la palma de la mano, grita: "Hoy te pelan, Pedro". Un augurio muy adecuado para describir una destrucción tan violenta: 12 a 2.

Los jugadores cruzan la cancha corriendo, ansiosos de llegar al final. Mercedes se aferra al esquema que le ha ayudado a remontar el cerro de lo posible. Alterna entre las bolas sutiles puestas en el medio y los bombazos vigorosos sobre el fondo. El Pedro está agotando sus combinaciones de palabrotas e insultos sobre el Puyoso y el Chuqui, quienes contestan con igual enjundia y mentadas de madre. Cuando el marcador marca 8 a 4 a favor de las damas, el Puyoso pide un minuto para reorganizarse. "Pare la bola - grita el árbitro-, un minuto para el Pedro y una guata para el juez”, ordena desde arriba, en medio de la noche, como si ordenara al universo.

Es solo un minuto añadido a la agonía, no hay nada que hacer. Karina y el Tobi ríen ruidosamente con cada nuevo punto. Mercedes permanece seria. Nada parece capaz de aflojar las cadenas de sus emociones. Gana 11 a 8. Todo está dicho, pero nada está escrito. Justo en el minuto de las definiciones, el Tobi deja pasar por mala una bola que golpea justo sobre la línea. El juez se alegra y marca el cambio. Solo entonces Mercedes Mena, la mejor ecuavoleyvolista profesional de esta ciudad, arranca de sus entrañas una orden larga y vigorosa, que sin que ella lo sepa en ese momento, resume toda su vida: "Sigan jugando... todavía no ganamos". Y es verdad, pienso yo mientras se asienta el último punto, aún no ha ganado -aún no hemos ganado- casi nada. 